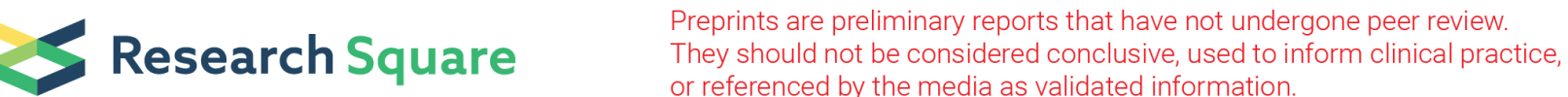

\section{Correlation Between he Ratio Pipp-R and Nips and Inter-Rater Reliability to Evaluate Pain During the Procedure Suction in Newborn Premature}

NAYARA RODRIGUES GOMES OLIVEIRA ( $\sim$ ft.nayrgomes@gmail.com )

Goias Federal University - GFU - Medical School

CIBELLE MARTINS ROBERTO FORMIGA

State University of Goias - SUG - Campus ESEFFEGO

BRUNA ABREU RAMOS

Goias Federal University - GFU - Medical School

RAFAELA NOLETO DOS SANTOS

State University of Goias - SUG - Campus ESEFFEGO

NAYARA NUBIA DE SOUSA MOREIRA

Goias Federal University - GFU - Medical School

PATRICIA GONÇALVES EVANGELISTA MARÇAL

Goias Federal University - GFU - Medical School

WALDEMAR NAVES DO AMARAL

Goias Federal University - GFU - Medical School

\section{Research Article}

Keywords: evaluation, pain, validity, preterm

Posted Date: October 15th, 2021

DOl: https://doi.org/10.21203/rs.3.rs-956847/v1

License: (9) This work is licensed under a Creative Commons Attribution 4.0 International License.

Read Full License 


\section{Abstract}

Objectives:To verify the Correlation between the Neonatal Infant Pain Scale (NIPS) and Premature Infant Pain Profile - Revised (PIPP-R), the internal consistency of each scale, and assess the reliability between evaluators in the assessment of pain during the aspiration procedure in premature newborns.

Methods: an observational, prospective study. Participated in the study, 50 infants who met the following criteria for inclusion: Newborn (NB) preterm (GA> 26 weeks and $<36$ weeks and five days) with low birth weight $(<2500 \mathrm{~g})$, hemodynamically stable, with minimal sedation or without sedation or mechanical ventilation in CPAP or catheter nose of 02 or the air environment that needed to perform the procedure of vacuum in the period of hospitalization. The evaluation of the newborns occurred during three different aspiration procedures; aspiration 1 (no intervention), aspiration 2 (use of gentle touch), and aspiration 3 (use of sucrose). They have applied two evaluation instruments, NIPS and PIPP-R. that Cronbach's alpha determined the internal consistency, reliability between evaluators by the coefficient of Correlation intraclass, validity competitor by Spearman test.

Results: Internal Consistency was high for NIPS ( $r=0.824)$ and moderate for PIPP-R (0.655). Reliability between raters was high respectively in the three conditions $0.991 ; 0.987 ; 0.993$ on the NIPS scale and $0.997 ; 0.986 ; 0.977$ on the PIPP-R scale. One observed concurrent validity Only in the first aspiration.

Conclusion: the NIPS seems to have a better utility clinic than PIPP-R; however, the two scales showed good reliability among the evaluators, and internal consistency, being a good choice for evaluation of pain during the procedure of aspiration.

\section{Introduction}

The review of the definition of pain happened by the International Association for the Study of Pain (IASP) as an unpleasant emotional and sensitive personal experience, which may or may not be related to actual or potential tissue damage. However, the exposure repeated for pain may damage the short and long term as irritability, altered sleep, hypersensitivity to painful stimuli, and cognition problems ${ }^{(1-3)}$.

Newborn premature babies often need invasive procedures andcare in units Therapy Intensive Neonatal (NICU), generating pain and stress neonatal ${ }^{(4-6)}$.

One study by Cong etal. observed that 50 newborns prematurely passed 643 painful procedures acute during all the hospitalization in the NICU, being the equivalent to 23 painful procedures per day ${ }^{(7)}$. Many professionals considered the painful procedures performed daily in neonates suction endotracheal and/or the various air as the most frequent procedure and further cause pain in newborns ${ }^{(8-11)}$.

The great challenge in assessing pain in newborns is evaluating one phenomenon (Pain) the most extensive translation is verbal in one being that still no voice. By professional observation, it is possible to conclude that the performed assessment of pain through the physiological,hormonal, by behavioral 
changes is a response to this pain ${ }^{(1)}$. Unfortunately, however, there is no standard gold assessment identified in routine clinical practice to quantify the pain in neonates ${ }^{(5)}$.

The studies and trials by clinicians used the cortisol level as a biomarker of pain states and stress; however, it is not feasible to evaluate real-time pain considering deciding on the treatment, as there is a considerable delay in obtaining the results ${ }^{(4)}$.

The American Academy of Pediatrics (AAP) recommends using reliable tools in assessing neonatal pain, as these are essential for the classification and management of pain. However, the choice of one instrument valid, reliable, feasible, and practical for assessing pain has been one challenge ${ }^{(12)}$.

Although there are more than 40 types of instruments for evaluating pain neonatal, only some of the used tools in units of Therapy Intensive Neonatal, although various Pain scales being available, the most frequently used are the PIPP and the NIPS ${ }^{(4.13)}$.

Inadequate pain assessment in preterm newborns is a persistent problem. One of the significant challenges of health professionals working in the NICU is to perform evaluations more accurately for pain. The use of adequate scales to assess pain in preterm infants is essential for effective treatment and pain management ${ }^{(14)}$. In the study of Xie et al., to compare four validated scales for assessment of neonatal pain, despite all show good internal consistency and high reliability, it suggests it is that the PIPP and the NIPS have good utility practice and are the best choice for assessment in babies premature infants submitted to heel puncture. There were no founding studies to compare the two scales during the aspiration procedure.

In this context, the study aimed to verify the Correlation between the Neonatal Infant Pain Scale (NIPS) and the Premature Infant Pain Profile - Revised (PIPP-R), the internal consistency of each scale, and to assess the reliability and agreement between the two evaluators to assess pain during the aspiration procedure in premature infants, to provide references that to help the professionals to choose and use best the instruments in the evaluation of pain neonatal.

\section{Methods}

The mentioned study is a prospective observational one. The staff participated in the survey, newborn preterm both sexes, with low weight at birth, admitted to the Neonatal Intensive Care Unit (NICU) of the Hospital and Maternity Hospital Iris city of Goiania. They adopted the following inclusion criteria: Newborn preterm (Gestacional age (GA) $>26$ and $<36$ weeks and five days), with low weight at birth $(<2500 \mathrm{~g})$, hemodynamically stable, with minimal sedation $(<0.3 \mathrm{mcg} / \mathrm{kg}$ fentanyl), or without sedation of ventilated mechanically or Continuous Positive Airway Pressure (CPAP) or catheter nose of oxygen or in air environment with cardiac and respiratory monitoring, which were not presenting discomfort or respiratory oxygen saturation drop and it need perform the procedure of extraction in a period of stay in 
the NICU. Exclusion criteria were: Newborns with genetic syndromes, major malformations, and congenital infections.

These infants, those who met the criteria for eligibility, were allocated and submitted to three procedures of aspiration and one without intervention and two with interventions (sucrose and gentle touch), were performed at three different times with an interval of at least 48 hours between them. All the Preterm newborn (PTNBs) remained without manipulation by at least five minutes before the procedure of aspiration. The shooting began thirty seconds before the process, having the suction duration on average of a minute to a minute and a half as the unit protocol plus the recovery time after aspiration of another thirty seconds, with sufficient quality to observe the expression and movements of the limbs, the edited voices eliminated bias. The edited vídeos, organized by a person, did not have a knowledgeable technician in the area of health.

As pain assessment instruments, two validated used scales, the Neonatal Infant Pain Scale (NIPS) and the Premature Infant Pain Profile - Revised (PIPP-R). The rankings were applied separately by two raters, masters and experts in Physical Therapy Pediatrics and Neonatal with extensive technical experience in Therapy Intensive Neonatal.

The Neonatal Infant Pain Scale Scale (NIPS) was developed based on the scale Children's Hospital of Eastern Ontario Pain Scale (CHEOPS) for neonates greater than 24 weeks who do not show commitment. It is a multidimensional pain assessment tool for preterm and term newborns; it is easy to understand and clinically apply. It was possible to assess six behavioral response indicators to acute procedural pain. The indicators include movements of the face, crying, regular breathing, activity motor of arms and legs, and sleep-wake state. It was adapted and translated by Motta in $2013^{(15-17)}$.

The NIPS assesses five behavioral factors (facial expression, crying, arms, legs, and behavioral state) and a physiological factor (respiratory pattern), each item being assigned scores of 0 or 1 (except for the crying thing, which has a score of 0 to 2 . Thus, the scale provides a total score ranging from 0 to 7 points, values greater than 3 indicating the presence of pain ${ }^{(18)}$.

The Premature Infant Pain Profile- Revised (PIPP-R) is a tool multidimensional and compound that evaluates pain acute in newborn premature and a term, though one analysis of seven indicators behavioral referring to movements facial (protrusion of brow, eyes tight and nasolabial folds) and physiological indicators (frequency heart and saturation of oxygen) and contextual (age pregnancy and state of sleep and wakefulness). It was translated and adapted to Portuguese by Bueno et al. in 2013 (17, 19).

Physiological and behavioral items are scored numerically on a four-point scale $(0.1,2,3)$, affecting changes in each variable from baseline values. However, scored contextual items are at the beginning of the pain assessment (before the baby is touched). Unlike behavioral and physiological items that receive higher scores, the more significant the changes from baseline, the GA and Behavioral Status scored items in the assessment in descending order $(3.2,1.0)$ to explain the physiological differences related to 
prematurity. Thus, the maximum attainable score is 21 points for premature babies ( 28 weeks of GA) and 18 points for babies born at term ${ }^{(17,19)}$.

The way to facilitate its use by the original version was recently revised and translated to the language Portuguese by Bueno et al. in 2019. The PIPP-R, despite the same indicators, has changed the method of scoring. GA and scored behavioral state items if there are changes in any other variable. The score ranges from 0 to 21 points, classified as no pain or mild pain with scores from 0 to 6 , soft to moderate pain values of 6-12 points, and average to severe pain scores greater than $12{ }^{(20)}$.

Initially, premature newborns with low birth weight were identified through an active search of medical records and admitted to the NICU. Then, there were approached guardians within the unit for an interview with the mother or guardian. Due to the complexity of the research, many asked for the Free and Informed Consent Form (FICF) to read together. After clarifying all the questions, the researcher in charge held to sign the term of consent free and clear. They noted the main features in a script containing the main information newborn, such as type of delivery, birth weight, Apgar score at 1 and 5 minutes, complications of health in phase neonatal.

The performed study was according to the Guidelines and Norms Regulating of Research Involving Being Human (Resolution 466/12 of the National Council of Health) and approved by the Committee Ethics in Research of the Hospital and Maternity Dona Iris by CAAE: 2894555.

Statistical analysis was carried out in an organized database in the program SPSS ( Statistical Package for Social Sciences, 23.0) and was considering the significance level of $5 \%(p<0.05)$ in all analyzes inferential.

The Intraclass Correlation Coefficient (ICC) was used to assess the reliability of scores between two evaluators ( $A$ and $B$ ) in the outcomes of pain perception by the NIPS and PIPP-R instruments. The ICC was calculated for the individual and mean scores, and the used Cronbach's Alpha to assess the internal consistency between the items of the tests applied. The parameters used to consider the ICC results were: ICC $>0.90$ (excellent), ICC between 0.90 and 0.89 (excellent), ICC between 0.71 and 0.79 (acceptable), and ICC $<0.70$ (not permitted) ${ }^{(21)}$.

The performed Kolmogorov-Smirnov statistical test verified the normality of data distribution. The distributed Pain assessment outcomes were unsatisfactory, opting for the use of non-parametric statistics. Spearman's Correlation used examination assessed the Correlation between the NIPS and PIPP-R scales.

\section{Results}

In this study, the biological data had the following results: there were 50 premature infants, $26(52 \%)$ sex female, 24 (48\%) of the sex male, age gestational average of 28 weeks $(24,42-35,41)$, weight at birth, 


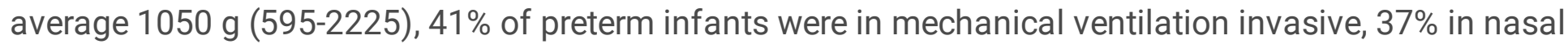
CPAP, $22 \%$ in oxygen therapy.

Table 01

Characterization of the sample $(n=50)$

\begin{tabular}{|ll|}
\hline Características dos RNs & Valores \\
\hline Sex & $24(48)$ \\
\hline Male (\%) & $26(52)$ \\
\hline Female (\%) & $1050(595-2225)$ \\
\hline Birth Weight (grams) & \\
\hline Med (min - max) & $28(24,42-35,14)$ \\
\hline Gestational Age (GA) (semanas) & $8(16)$ \\
\hline Med (min - max) & $42(84)$ \\
\hline Adequacy for the Gestational Age & $41(82)$ \\
\hline SGA f(\%) & $37(74)$ \\
\hline AlG f(\%) & $21(42)$ \\
\hline Mechanical Ventilation (\%) & \\
\hline CPAP (\%) & \\
\hline Oxigen (\%) & \\
\hline $\begin{array}{l}\text { Med= medium, min = minimum value; max= maximum value; } f=\text { frequency; } \% \text { percentage; SGA = } \\
\text { Smal for Gestational Age; BGA= Big for Gestational Age. }\end{array}$ \\
\hline
\end{tabular}

One hundred and fifty evaluated footage and each PTNB in three filmed situations (aspiration without intervention, aspiration with the gentle touch, aspiration with the use of sucrose). The median scores during the three aspiration procedures on the NIPS scale were, respectively, 4.27 (3.49 - 5.09); 3.14 (2.47 3.81); 2.19 (1.57 - 2.81), while in the PIPP-R scale, they were 10.04 (8.92 - 11.16); 8.53 (7.74 - 9.32); 7 (6 - 8). The agreement between raters on the NIPS scale was 0.983 for aspiration without intervention, 0.975 for aspiration with a gentle touch, and 0.985 for aspiration with sucrose. Already in scale, PIPP-R were respectively $0.995 ; 0.973 ; 0.955$, as shown in figure 2 .

Overall, Cronbach's alpha indicates that the internal consistency of the NIPS and PIPP-R scales were 0.824 and 0.655 , respectively.

Spearman's Correlation between the NIPS and PIPP-R scales was significant only in the first aspiration procedure $\left(r=0.668\right.$ for examiner $A, r=0.660$ for examiner $B$, both with $p<0.001^{*}$ ). 


\section{Discussion}

This study provides reliability measures between two scales used to assess pain in preterm infants during a painful procedure. We evaluated the Correlation between the NIPS and PIPP-R scales, the internal consistency of each scale, and the reliability between the two evaluators in assessing pain during the aspiration procedure in premature newborns. Both scales were sensitive in identifying pain. In evaluating pain in the three aspiration procedures, we note that the pain was more evident in the vacuum, not intervention. We could see a difference in pain evaluation in the three procedures through the two scales and that the pain is less when used methods no pharmacological pain relief.

Identifying reliable instruments will help the care team better control pain, improving the quality of care for vulnerable newborns. In addition, our study corroborates the study by Bueno et al. ${ }^{(20)}$ which initially validated the Brazilian version of the PIPP- $\mathrm{R}$, which showed that the scores on this scale were responsive both to painful stimuli and to different pain relief strategies.

In the study by Peng et al. using the PIPP to assess pain in 109 newborn premature during the procedure of puncture of the heel, observed one risk lowest of pain moderate and severe in infants who received combinations of suction, milk breast, and bending facilitated when compared to babies who received routine care ${ }^{(22)}$. In this study, despite a decrease in total score range PIPP-R, the pain was rated with moderate in three procedures.

Reliability and internal consistency ${ }^{(14)}$, in the observational study by Xie et al. ${ }^{(14)}$, four assessed scales (Neonatal Facial Coding System (NFCS), Doulleur Aiguedu Nouveau-Née (DAN), NIPS, PIPP) for validity in assessing pain during blood collection from the heel of 111 preterm infants observed that all four rankings were high. Our results showed high reliability and internal consistency on the NIPS scale and moderate reliability and inner surface on the PIPP-R scale. It has found no study to evaluate scales of pain neonatal during the procedure of aspiration.

Huang et al. ${ }^{(23)}$, when evaluating 90 premature newborns and terms of invasive mechanical ventilation, obtained results similar to those of the present study, in which the Cronbach's alpha of the three scales was an acceptable score. Thus, it provided evidence for good reliability between the Neonatal-Pain, Agitation and Sedation Sclae (N-PASS), NAPAS, and PIPP-R scales for neonates on mechanical ventilation. However, the internal consistency of the N-PASS scales and NAPAS was higher than PIPP-R. The reason to explain with slight differences in the numbers and graduation of behavioral or physiological indicators and the contextual factor, Gestational Age, affects the internal consistency of the PIPP-R ${ }^{(23)}$.

In Brown et al. ${ }^{(20)}$ study for adaptation and scale validation PIPP-R in Brazil, three nurses evaluated two sets of data studies randomized to assess pain in newborns using the PIPP scale. In the first study, 47 neonates analyzed with a mean gestational age of 35.4 weeks underwent heel puncture. In the second study, 84 babies with an age mean of 36.7 weeks underwent catheter exchange. The nurses indicated it 
was necessary to train further on the score of PIPP-R and the importance of establishing a behavioral state base before handling the baby, often a step forgotten by them (20). This finding was similar to other studies of psychometric properties since a more significant internal without any demonstrated consistency of the PIPP-R, especially compared to the NIPS scale.

The professionals couldn't facilitate the use of the assessment tool pain by professionals with the original version of the PIPP scale, recently been revised ( PIPP-R). Despite the maintenance of the indicators, the modified scoring method, in hands saturation of oxygen, demonstrated facial activity facial ( arching the brow, eyes tight and nasolabial folds), behavioral state baseline, and age pregnancy. Studies have shown the validity of the construct, convergent validity, and high Correlation between the scores of PIPP- range R and PIPP pain relief for different strategies as, for example, glucose, glucose associated with the suction, and breastmilk, as well as for other procedures, as puncture heel and vein in babies to term and preterm infants $(20,24)$.

Before the painful event of high based scores on baseline characteristics, the changing of behavioral states and GA scores minimized the effects. n PIPP-R, GA and behavioral. This study brought High interrater reliability for NIPS and PIPP-R with ICCs greater than 0.90 (21). The findings corroborate the results found in the survey by Motta et al. ${ }^{(18)}$, which performed the cross-cultural adaptation of the NIPS in Brazil with an assessment of $60 \mathrm{NBs}$ by six nurses and showed excellent reliability among observers. In addition, in the study by Gibbins et al. ${ }^{(24)}$, there was a high agreement among evaluators using the PIPPR scale.

In a prospective crossover study, one hundred ninety-five bedside nurses evaluated 202 hospitalized infants divided into three gestational age groups (26-31, 32-36, and $>37$ weeks) in three different NICUs during painful procedures. The high degree of agreement between PIPP-R expert evaluators and nurses in the assessment of during painful (0.92) and non-painful (0.87) procedures suggests that the instrument is appropriate, reliable, and consistent with all babies over 26 weeks gestation in the NICU during the evaluation in time real ${ }^{(24)}$.

The NIPS Brazil scale showed excellent interobserver and intraobserver reliability, generating similar coefficients to those of the original scale version. The internal consistency of the NIPS was satisfactory ( Cronbach's alpha of 0.762 ) in the assessment of pain in 60 newborns during vaccination ${ }^{(18)}$. Thus, the study of the NIPS scale permitted the high internal consistency demonstration.

Although the NIPS is a validated scale that presents psychometry well established, high reliability among the evaluators, consistent internal and concurrent validity for assessing pain in neonates, it may not be sensitive enough to evaluate the behavior of babies who need intensive care. The concurrent validity between the NIPS and NAPAS (Infant Neonatal Acute Pain Assessment Scale) in the evaluation of 34 neonates undergoing the 60 procedures painful (puncture of the heel and aspiration) were high (0.751 and 0.873$)^{(26)}$. Therefore, in the present study, the psychometric findings were satisfactory for the NIPS scale. 
The result of the Spearman test allows the observation of a significant correlation between the scales NIPS and PIPP-R only the first condition $(p<0.001)$ which may have occurred is in the first condition aspiration was performed without any intervention non - pharmacological, and thus the pain was more evident and more easily assessed.

In the study of Xie et al., conducted with 111 babies prematurely undergoing heel blood collection in the $\mathrm{NICU}$, to evaluate the efficacy of four scales for assessment of pain neonatal, the nurses consider the PIPP easy to use, easy to score, and more accurate. On the other hand, NIPS took less time, probably because its items are easier to remember and evaluate. The study indicated that the PIPP and NIPS are the best choices compared to the other two scales. In routine intense within the NICU, doctors prefer to choose a range of easy-to-use, easy scores, which consumes little time and has good viability clinic (14). The present study didn't analyze the scales' application time; however, evaluators considered the rankings easy to understand and apply.

In the present study, the NIPS scale seems to have better clinical feasibility and applicability when compared to the PIPP-R scale since its scores are easy to understand and more concise. However, the NIPS scale does not measure pain intensity.

This study has strong points related to the study's design. The evaluators are professional experts with extensive experience in Neonatal Physiotherapy and have used two instruments validated and widely used in clinical practice. However, it presented the limitation of not having assessed the professionals' preference with applying the scale and practical applicability of the instruments in a sample of physical therapists in the area.

So choose one as valid, reliable, feasible, and practical aids the health professionals to make the best control of pain, improving the quality of care to the patient, especially of newborn premature that are most vulnerable.

Despite the difficulties encountered by realizadação in this study, the results showed that the two scales showed good Correlation only during the suction procedure without intervention. The pain was more evident in the premature newborn sample. In addition, the scales showed good reliability, internal consistency, and reliability among the evaluators. Thus, we suggest that both the PIPP-R and the NIPS good clinical validity and are one good choice to evaluate babies' pain during the procedure aspiration.

This study provides a reference to assist the professionals of health who work in the NICU to choose and use best the pain assessment scales in premature newborns. We suggest that further developed studies better apply these scales, particularly during the vacuum procedure, and evaluate the pain before, during, and after the process.

\section{Abbreviations}


CHEOPS - Children's Hospital of Eastern Ontario Pain Scale

CPAP - Continuous Positive Airway Pressure

DAN - Douleur Aiguedu Nouveau-Née

FICF - Free and Informed Consent Form

GA - Gestacional Age

IASP - International Association for the Study of Pain

ICC - Intraclass Correlation Coefficient

NAPAS - Infant Neonatal Acute Pain Assessment Scale

NB - Newborn

NFCS - Neonatal Facial Coding System

NICU - Neonatal Intensive Care Unit

NIPS - Neonatal Infant Pain Scale

N-PASS - Neonatal-Pain, Agitation and Sedation Scale

PIPP - Premature Infant Pain Profile

PIPP-R - Premature Infant Pain Profile - Revised

PTNB - Preterm Newborn

SPSS - Statistical Package for Social Sciences

\section{Declarations}

\section{Ethics approval and consent to participate}

Initially, premature newborns with low birth weight were identified through an active search of medical records and admitted to the NICU. Then, there were approached guardians within the unit for an interview with the mother or guardian. Due to the complexity of the research, many asked for the FICF to read together. After clarifying all the questions, the researcher in charge held to sign the term of consent free and clear. They noted the main features in a script containing the main information newborn, such as type of delivery, birth weight, Apgar score at 1 and 5 minutes, complications of health in phase neonatal. 
The performed study was according to the Guidelines and Norms Regulating of Research Involving Being Human (Resolution 466/12 of the National Council of Health) and approved by the Committee Ethics in Research of the Hospital and Maternity Dona Iris by CAAE: 2894555.

\section{Consent for publication}

Not applicable.

\section{Availability of data and materials}

The datasets used and/or analysed during the current study are available from the corresponding author on reasonable request.

\section{Competing interests}

The authors declare that they have no competing interests.

\section{Funding}

Funded by the authors.

\section{Authors' contributions}

Oliveira, NRG, conceived and designed and carried out the research, collected data from patients at the Hospital and Maternity Hospital in Goiânia, interpreted the data, and wrote the manuscript. Formiga, CKR conceived and designed the research, contributed to the manuscript's critical discussion, and assisted in editing the manuscript. Amaral, WN interpreted the data, contributed to the critical discussion of the manuscript. Ramos, BA participated in data collection and evaluation of procedures performed on newborns. Santos, RN, participated in data collection and assessment of operations performed on newborns. Moreira, NNS and MARÇAL, PGE contributed to the critical discussion of the manuscript and assisted in editing the manuscript. All authors approved the article's final version, and we attest that this manuscript has not been published elsewhere and is not under consideration by another journal.

\section{Acknowledgements}

Not applicable.

\section{References}


1. Sarmento GJ V. Hospital Physiotherapy in Pediatrics. HANDLE. Carvalho EFT, Hage YE, editors. 2018. 132-141 p.

2. DEISE Petean Bonutti dimensioning of procedures painful and interventions for relief of pain acute in premature Ribeirao Black,. 2014.

3. Srinivasa NR, Carr DB, Cohen M, Finnerup NB, Flor H, Gibson S. Revised definition of pain by the International Association for the Study of Pain: concepts, challenges and commitments. 2020;1-8.

4. Maxwell LG, Fraga M V., Malavolta CP. Assessment of Pain in the Newborn: An Update. Clin Perinatol. 2019;46(4):693-707.

5. Roué JM, Rioualen S Gendras J Misery L, M Gouillou, J. Sizun Multi- modal pain assessment: Are near-infrared spectroscopy, skin conductance, salivary cortisol, physiologic parameters, and Neonatal Facial Coding System interrelated During venepuncture in healthy, term neonates? J Pain Res. 2018;11:2257-67.

6. Xie W, Wang X, R Huang, Chen Y, Guo X. Assessment of four pain scales for Evaluating procedural pain in premature infants undergoing heel blood collection. Pediatr Res [Internet]. 2020;(January):18. Available from: http://dx.doi.org/10.1038/s41390-020-1034-z.

7. Cong X, Wu J, Vittner D, Xu W, Hussain N, Galvin S, et al. The impact of cumulative pain/stress on neurobehavioral development of preterm infants in the NICU. Early Hum Dev [Internet]. 2017;108:916. Available from: http://dx.doi.org/10.1016/j.earlhumdev.2017.03.003.

8. Sposito NPB, Rossato LM, Bueno M, Kimura AF, Costa T, Guedes DMB. Pain assessment and management in newborns admitted to the Neonatal Intensive Care Unit: Cross- sectional study. Rev Lat Am Nursing. 2017;25.

9. Gimenez IL, Arakaki V of SNM, Correa RM, Santos RS dos, Peres RT, Sant'Anna CC, et al. Neonatal Pain: characterization of the physiotherapist \& \# 039; s perception in the neonatal intensive care unit TT - neonatal pain: characterization of the perception of the physiotherapist unit of therapy intensive neonatal. Rev Paul Pediatr (Ed Port, Online). 2020;38:e2018178-e2018178.

10. Qiu J, Jiang Y Fei, Li F, Tong Qhong, Rong H, Cheng R. Effect of combined music and touch intervention on pain response and $\beta$ - endorphin and cortisol concentrations in late preterm infants. BMC Pediatr [Internet]. 2017;17(1):1-7. Available from: http://dx.doi.org/10.1186/s12887-016-0755$y$.

11. Zanelat CF, Rocha FR, Lopes GM, Ferreira JR, Gabriel LS, Oliveira TG e. The respiratory physiotherapy causes pain in newborns? A systematic review. Physioter in Mov. 2017;30(1):177-86.

12. Statement P. Prevention and Management of Procedural Pain in the Neonate: An Update. Pediatrics. 2016;137(2):e20154271.

13. Hartley KA, Miller CS, Gephart SM. Facilitated tucking to reduce pain in neonates: Evidence for best practice. Adv Neonatal Care. 2015;15(3):201-8.

14. Xie W, Wang X, R Huang, Chen Y, Guo X. Assessment of four pain scales for Evaluating procedural pain in premature infants undergoing heel blood collection. Pediatr Res. 2020;1-8. 
15. From Motta GDCP. Adaptation Transcultural and Validation Practice of Neonatal Infant Pain Scale for the use in Brazil. thesis [Internet]. 2013;1(1). Available from: https: //www.bertelsmannstiftung.de/fileadmin/files/BSt/Publikationen/GrauePublikationen/MT_GI obalization_Report_2018.pdf\% OA http://eprints.Ise.ac.uk/43447/1/India_globalization\% 2C society and inequalities\%28lsero\%29.pdf\%0Ahttps: //www.quora.com/What-is-the.

16. LM Battle of C. Assessment of Pain: Study Manual - Version 1. Trat the pain in the clinic. 2016;1:8192.

17. Guinsburg R. Assessment and treatment of pain in the newborn Assessing and treating pain in the newborn. J Pediatr. 1999;75(3):149-60.

18. Da Motta GDCP, Schardosim J, Da Cunha M. Neonatal Infant Pain Scale: Cross-Cultural Adaptation and Validation in Brazil. Journal of Pain and Symptons Management. 2015; 50(3):394-401.

19. Bueno M, Costa P, de Oliveira AAS, Cardoso R, Kimura AF. Translation and adaptation of premature infant pain profile to Portuguese. Text and Context Enferm. 2013;22(1):29-35.

20. Bueno M, Moreno-Ramos MC, Forni E, Kimura AF. Adaptation and Initial Validation of the Premature Infant Pain Profile-Revised (PIPP-R) in Brazil. Pain Manag Nurs [Internet]. 2019;20(5):512-5. Available from: https://doi.org/10.1016/j.pmn.2019.02.002.

21. Koo TK, Li MY. A Guideline of Selecting and Reporting Intraclass Correlation Coefficients for Reliability Research. J Chiropr Med. 2016;15(2):155-63.

22. Peng HF, Yin T, Yang L, Wang C, Chang YC, Jeng MJ, et al. Non- nutritive sucking, oral breast milk, and facilitated tucking relieve preterm infant pain during heel-stick procedures: A prospective, randomized controlled trial. Int J Nurs Stud [Internet]. 2018;77:162-70 Available from: http://dx.doi.org/10.1016/j.jjnurstu.2017.10.001.

23. Huang XZ, Li L, Zhou J, He F, Zhong CX, Wang B. Evaluation of three pain assessment scales used for ventilated neonates. J Clin Nurs. 2018;27(19-20):3522-9.

24. Gibbins S, Stevens BJ, Yamada J, Dionne K, Campbell-Yeo M, Lee G, et al. Validation of the Premature Infant Pain Profile-Revised (PIPP-R). Early Hum Dev [Internet]. 2014;90(4):189-93. Available from: http://dx.doi.org/10.1016/j.earlhumdev.2014.01.005.

25. Gibbins S, Stevens BJ, Yamada J, Dionne K, Campbell-Yeo M, Lee G, et al. Validation of the Premature Infant Pain Profile-Revised (PIPP-R). Early Hum Dev. 2014;90(4):189-93.

26. Pölkki T, Korhonen A, Axelin A, Saarela T, Laukkala H. Development and preliminary validation of the Neonatal Infant Acute Pain Assessment Scale (NIAPAS). Int J Nurs Stud [Internet]. 2014;51(12):1585-94. Available from: http://dx.doi.org/10.1016/j.jijnurstu.2014.04.001.

\section{Figures}




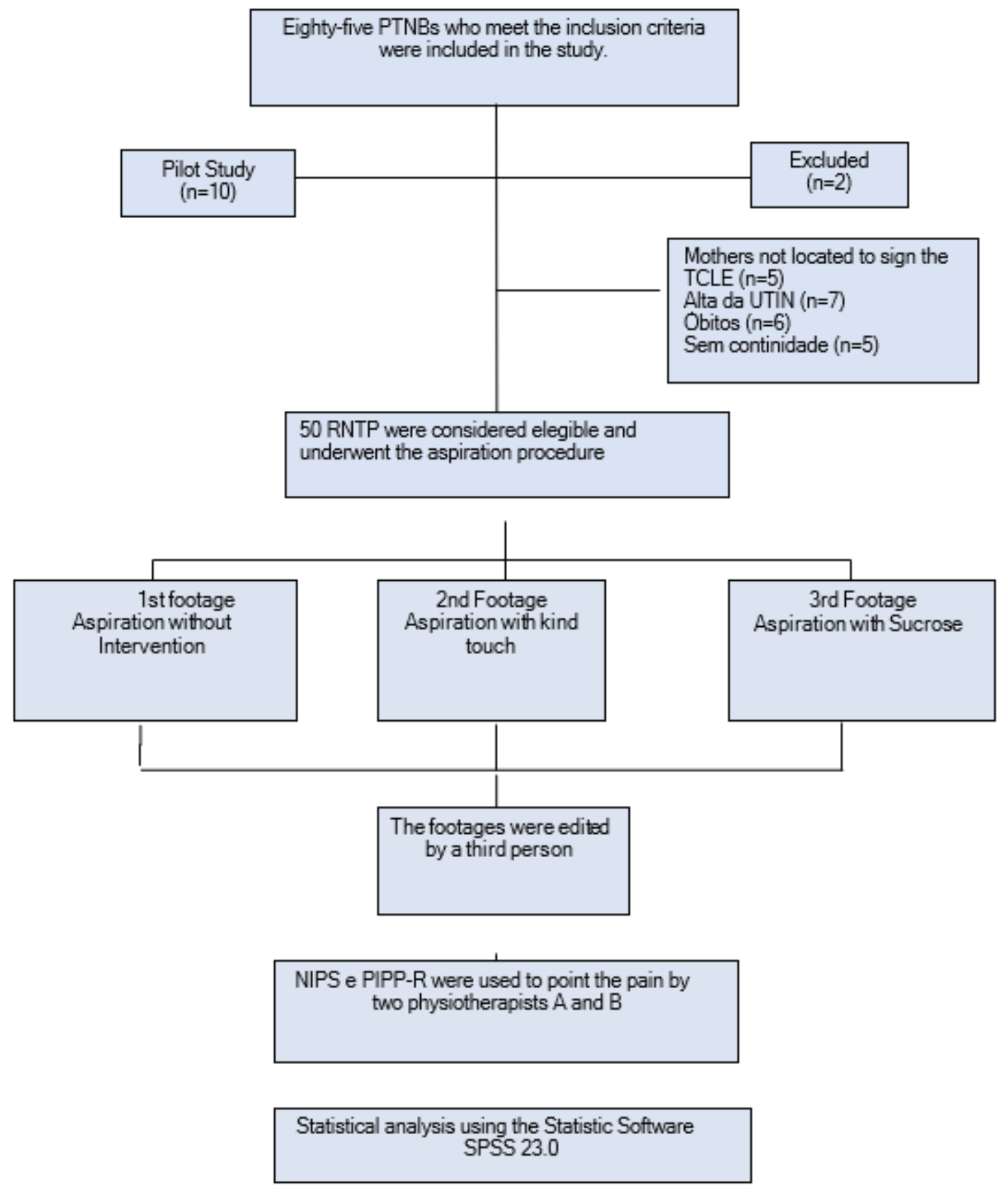

Figure 1

Study design flowchart. Goiânia, Goiás, 2020 
A)

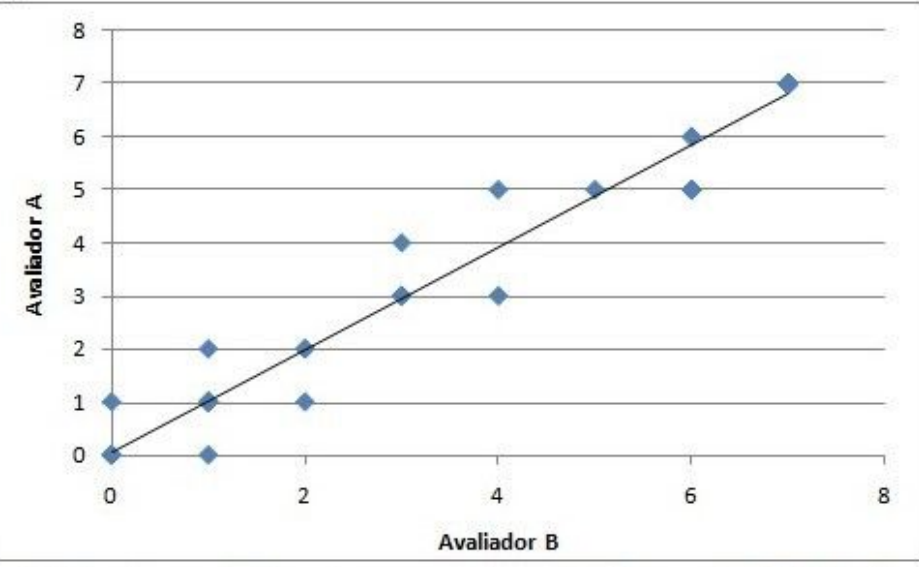

Gráfico de correlação entre os avaliadores A e B na aspiração I (NIPS) B)

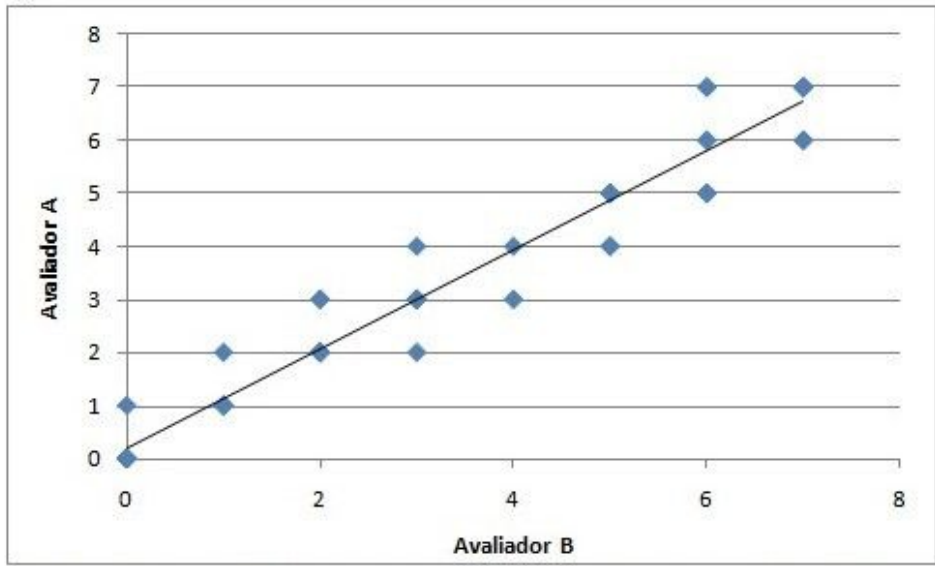

C)

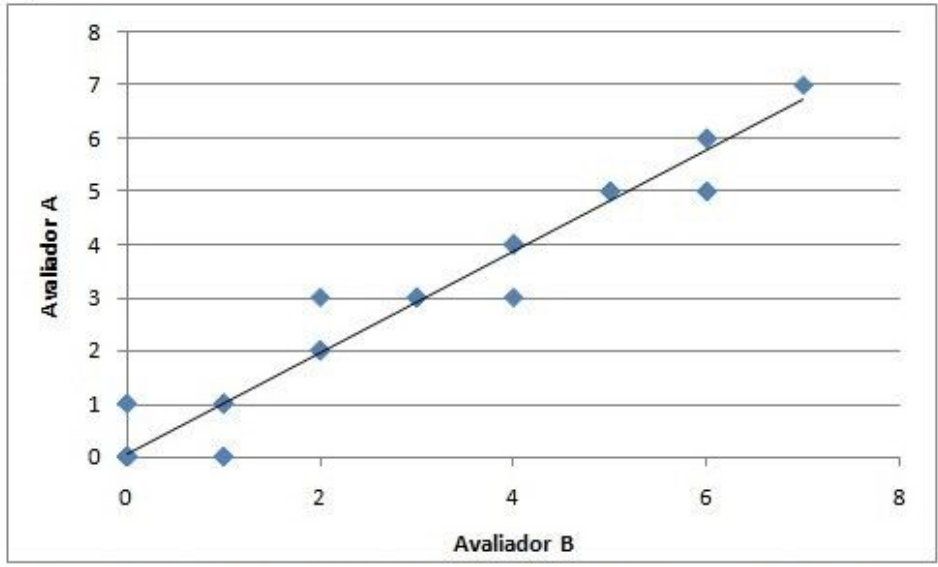

Gráfico de correlação entre os avaliadores A e B na aspiração III (NIPS)
D)

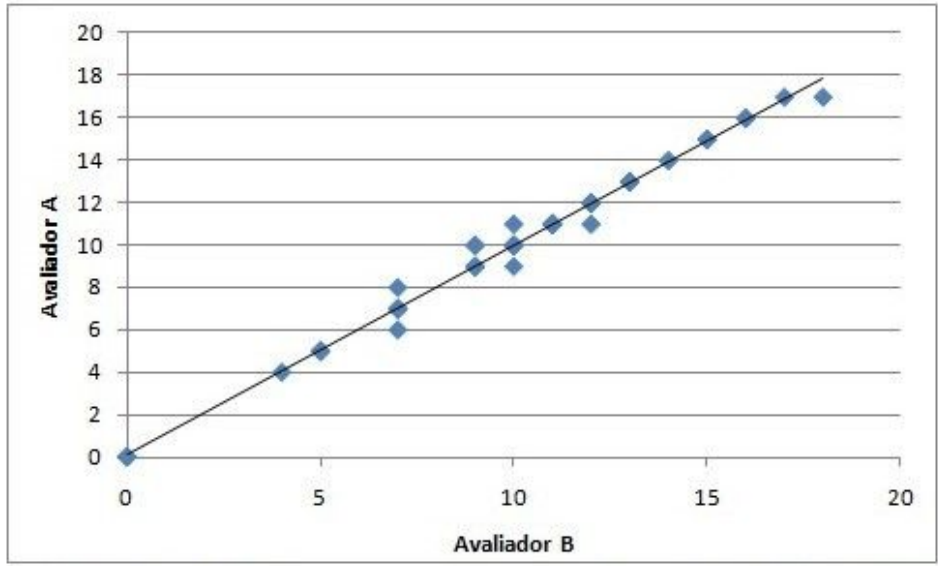

Gráfico de correlação entre os avaliadores A e B na aspiração I (PPIP-R) E)

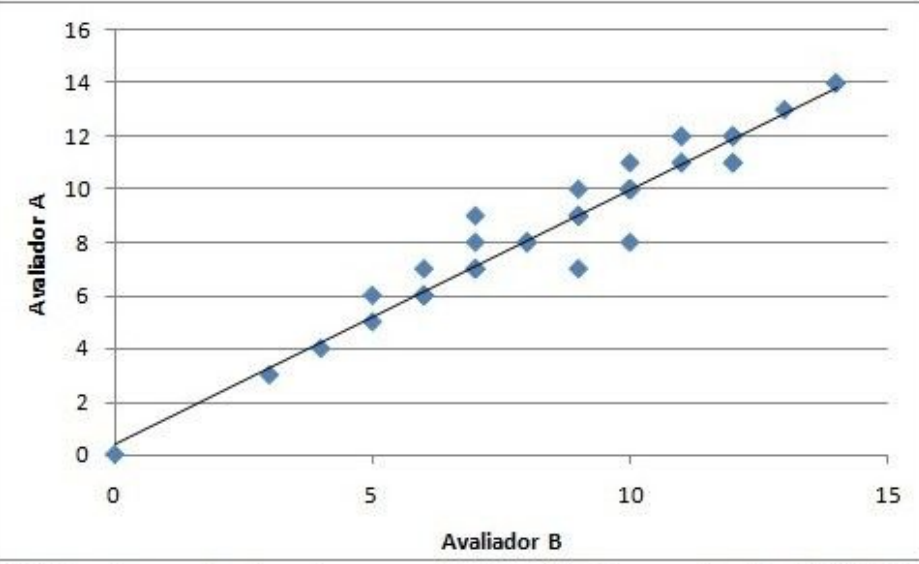

Gráfico de correlação entre os avaliadores A e B na aspiração II (PPIP-R) F)

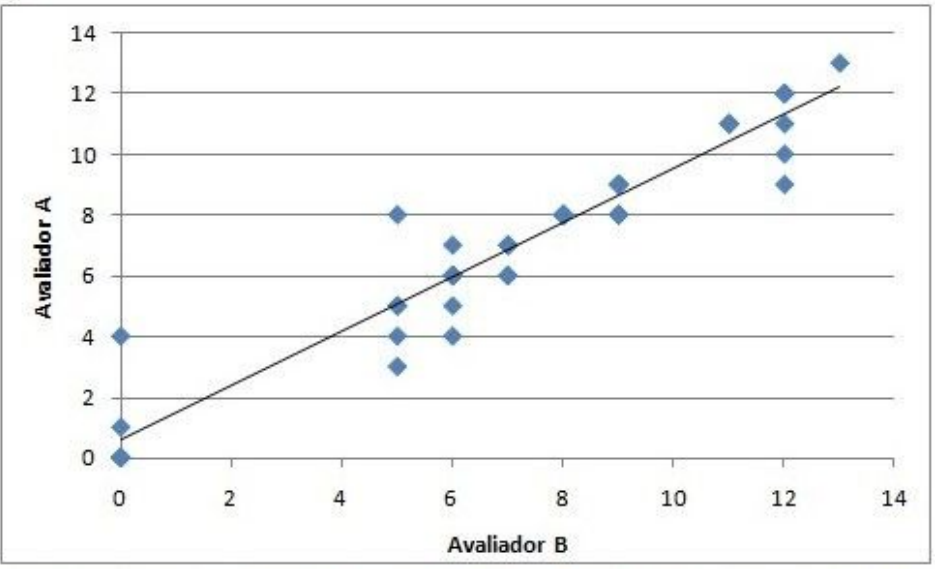

Gráfico de correlação entre os avaliadores A e B na aspiração III (PPIP-R)

\section{Figure 2}

Correlation between evaluators in the three aspiration procedures using the two scales NIPS and PIPP-R. 
A)

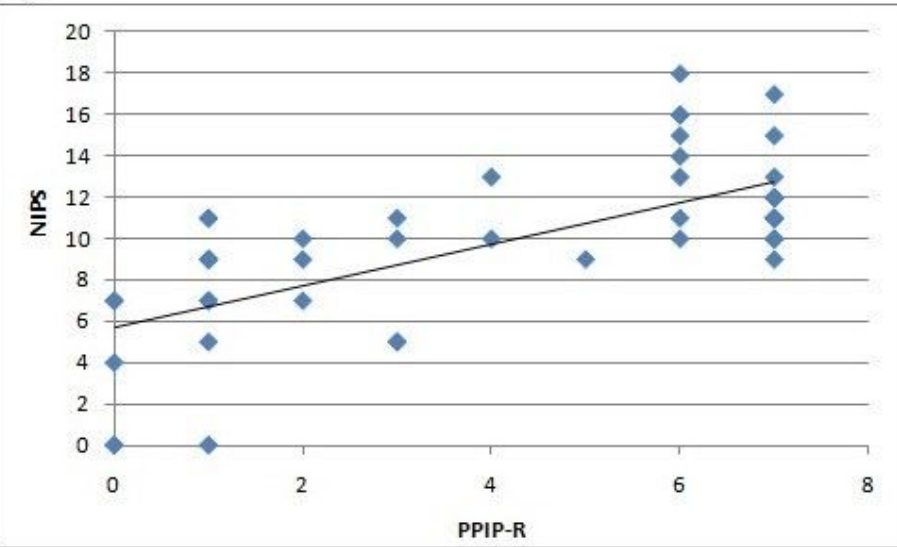

Gráfico de correlação entre os instrumentos NIPS e PPIP-R quanto ao avaliador A na aspiração I

B)

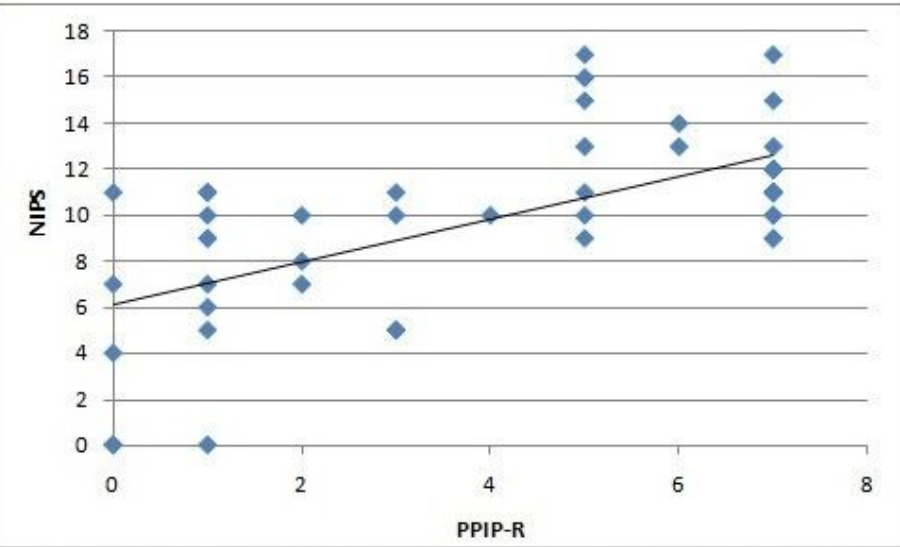

Gráfico de correlação entre os instrumentos NIPS e PPIP-R quanto ao avaliador B na aspiração I

C)

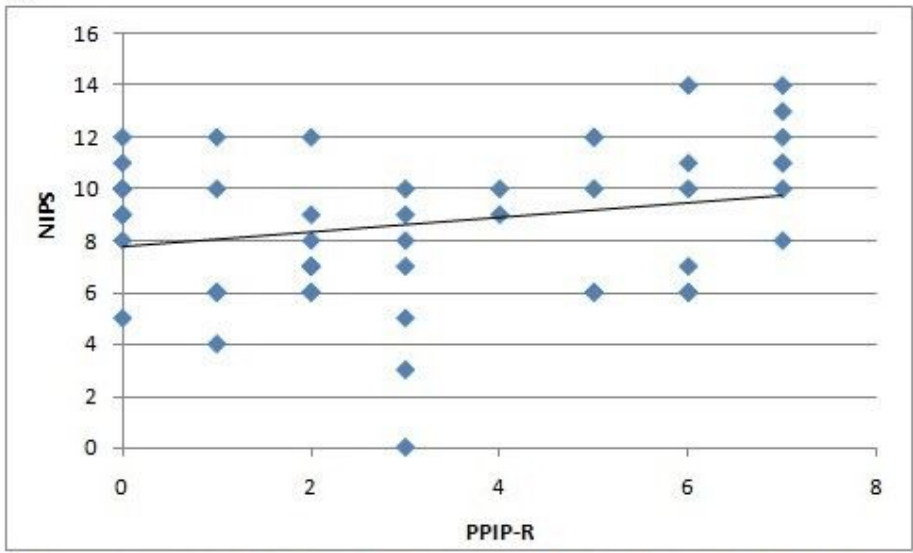

Gráfico de correlação entre os instrumentos NIPS e PPIP-R quanto ao avaliador A na aspiração ॥
D)

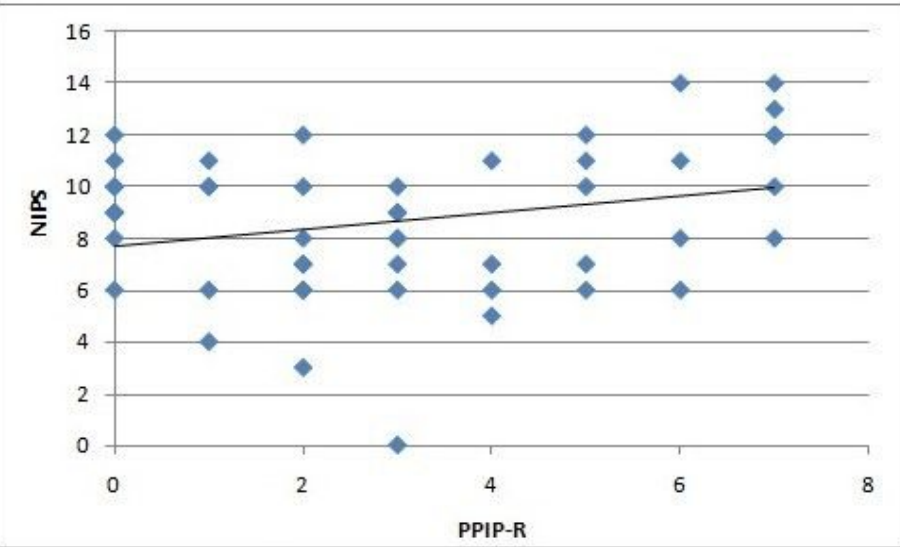

Gráfico de correlação entre os instrumentos NIPS e PPIP-R quanto ao avaliador B na aspiração ॥

E)

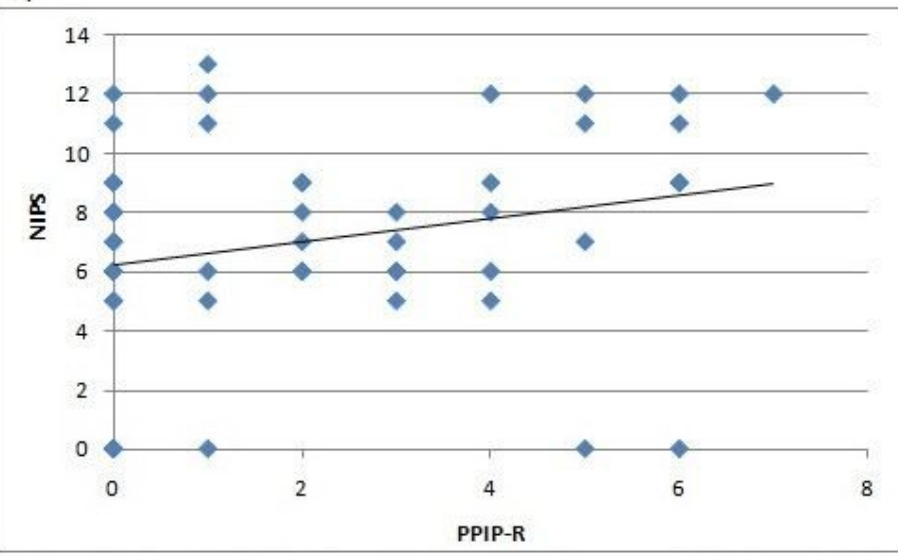

Gráfico de correlação entre os instrumentos NIPS e PPIP-R quanto ao avaliador A na aspiração III

F)

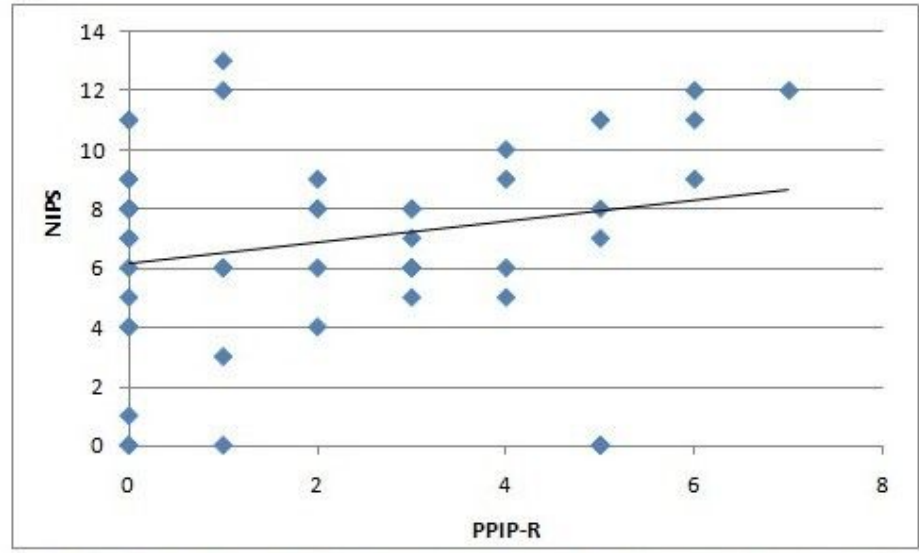

Gráfico de correlação entre os instrumentos NIPS e PPIP-R quanto ao avaliador B na aspiração III

\section{Figure 3}

Correlation between NIPS and PIPP-R instruments at the three aspiration moments of evaluators A and B. 